\title{
KEPUASAN PELANGGAN PO ROSALIA INDAH MENGGUNAKAN IMPORTANCE PERFORMANCE COMPETITOR ANALYSIS (IPCA)
}

\author{
Nia Budi Puspitasari*), Susatyo Nugroho W. P, Yoana Ellen Pertiwi \\ Departemen Teknik Industri, Fakultas Teknik, Universitas Diponegoro, \\ Jl. Prof. Soedarto, SH, Kampus Undip Tembalang, Semarang, Indonesia 50275
}

(Received: May 31, 2019/Accepted: August 19, 2019)

\begin{abstract}
Abstrak
Persaingan yang ketat antara perusahaan dalam pelayanan bus antar kota antar provinsi membutuhkan perbaikan pelayanan kualitas untuk mempertahankan pelanggan. Adanya ketidakpuasan pelanggan terhadap fasilitas dan layanan yang diberikan oleh PO Rosalia Indah menjadi suatu permasalahan yang harus diperbaiki sehingga dengan menerapkan metode ini dapat meningkatkan kualitas pelayanan PO Rosalia Indah dan loyalitas penumpang. Penelitian ini bertujuan untuk menganalisa kepuasan pelanggan PO Rosalia Indah dengan mempertimbangkan keberadaan pesaingnya yaitu PO Pahala Kencana dan memberikan rekomendasi perbaikan terhadap atribut fasilitas yang menjadi prioritas perbaikan. Penelitian ini menggunakan metode Importance Performance Competitor Analysis (IPCA). Pengambilan data dilakukan terhadap dua kelompok responden yaitu responden PO Rosalia Indah dan responden PO Pahala Kencana. Penelitian ini mengukur tingkat pelayanan kualitas berdasarkan 3 dimensi yaitu kendaraan (15 butir pernyataan), sopir dan kru (8 butir pernyataan) dan manajemen (13 butir pernyataan). Berdasarkan hasil pengolahan data dengan IPCA didapatkan bahwa terdapat 21 butir pernyataan yang masuk dalam kuadran Urgent Action dan memerlukan perbaikan. Rekomendasi perbaikan dilakukan dengan metode Numerical Group Technique (NGT) yang berasal dari lima ahli yang mengerti dalam bidang transportasi bus.
\end{abstract}

Kata kunci: kepuasan pelanggan; numerical group technique; IPCA

\begin{abstract}
[The Customer Satisfaction of PO Rosalia Indah using Importance Performance Competitor Analysis (IPCA)] The intense competition between companies in intercity bus services between provinces requires the improvement of quality services to retain customers. The existence of customer dissatisfaction with the facilities and services provided by PO Rosalia Indah becomes a problem that must be improved so that by applying this method can improve the quality of service Rosalia Indah PO and passenger loyalty. This research aims to analyze customer satisfaction of PO Rosalia Indah by considering the existence of its competitor that is PO Pahala Kencana and give recommendation improvement to the facility attribute which become the priority of improving. This research uses Importance Performance Competitor Analysis (IPCA) method. The data were collected from two groups of respondents namely PO Rosalia Indah and respondent's PO Pahala Kencana. This study measures the level of quality service based on 3 dimensions of the vehicle (15 points statement), driver and crew (8 points statement) and management (13 points statement). Based on the results of data processing with IPCA found that there are 21 items of statements that enter the Urgent Action quadrant and require improvement. The improvement recommendation was made by Numerical Group Technique (NGT) method which is derived from five experts who understand in the bus transportation field.
\end{abstract}

Keywords: customer satisfaction; numerical group technique; IPCA

*)Penulis Korespondensi.

E-mail: niabudipuspitasari@gmail.com

\section{Pendahuluan}

Transportasi merupakan sarana yang sangat penting dalam menghubungkan satu wilayah dengan 
wilayah yang berkaitan dengan banyak sektor terutama membantu kegiatan pengembangan perekonomian. Salah satu trasnportasi umum yang banyak diminati oleh masyarakat Indonesia adalah bus. Hal ini dikarenakan beberapa alasan yaitu fleksibilitas sehingga penumpang bisa memilih waktu keberangkatan, aksesibilitas yaitu dapat tiba di tempat terdekat tujuan utama penumpang dan harga tiket yang terjangkau. Selama 4 tahun terakhir menurut Kementrian Perhubungan terjadi penurunan penumpang bus sebanyak 5,97\% pada tahun 2015 yang dimulai dari tahun 2012 yaitu sebesar 5.917.156 menjadi 4.918.964 dan pada tahun 2016, penurunan penumpang bus sebesar 2,7\% menjadi 4,57 juta penumpang (Cahyaningrum \& Werdiono, 2015). Faktor yang menyebabkan penurunan seperti peningkatan penggunaan mobil pribadi, kereta api dan pesawat, peningkatan adanya mudik gratis oleh perusahaan hingga masalah fasilitas dan pelayanan bus yang kurang memuaskan.

PO Rosalia Indah merupakan salah satu perusahaan otobus ternama di Indonesia dan memenangkan penghargaan Perusahaan Otobus Terbaik 2014. PO Rosalia Indah (PO Rosalia Indah) memiliki berbagai kelas layanan yaitu Non AC, Patas AC, VIP, Eksekutif dan Super Eksekutif. Kelas bus yang banyak dipilih oleh penumpang adalah kelas Eksekutif karena dianggap memiliki fasilitas lengkap dan harga yang cukup terjangkau. Trayek Semarang-Jakarta merupakan trayek yang memiliki jumlah penumpang yang banyak menggunakan kelas bus Eksekutif.

Survei pendahuluan dilakukan terhadap penumpang bus yang mengindikasikan adanya ketidakpuasan penumpang seperti jarak antar kursi tidak ergonomis, suara mesin mengganggu, AC bocor dan bau, rak bagasi tidak memadai, sopir mengemudi ugalugalan, kedatangan bus tidak tepat waktu dan tidak ada fasilitas pengaduan. Persaingan di antara perusahaan otobus sangat ketat sehingga PO Rosalia Indah membutuhkan perbaikan kualitas pelayanan untuk mempertahankan penumpang dan tidak pindah pada perusahaan otobus lainnya. Salah satu pesaing PO Rosalia Indah yang memenangkan penghargaan Perusahaan Otobus Terbaik di Indonesia pada tahun 2015 adalah PO Pahala Kencana.

Tidak terpilihnya Rosalia Indah sebagai perusahaan angkutan AKAP non ekonomi terbaik tahun 2015 serta keluhan pada pelayanan fasilitas maka PO Rosalia Indah harus lebih memperhatikan dari aspek yang penting bagi penumpang yaitu pemberian kualitas pelayanan. Kualitas pelayanan menjadi hal yang penting dalam memaksimalkan kepuasan pelanggan dari perusahaan karena dapat meningkatkan loyalitas pelanggan dalam menggunakan jasa bus sehingga tidak akan berpindah pada perusahaan pesaing. Kepuasan pelanggan sendiri memiliki arti yaitu evaluasi secara sadar atau penilaian kognitif menyangkut apakah kinerja produk relatif bagus atau jelek atau apakah produk bersangkutan cocok atau tidak cocok dengan tujuan/pemakainya (Tjiptono, 2008). Menurut Parasuraman dalam Putri dan Nurcaya (2013) menyatakan bahwa terdapat lima dimensi yang menyangkut masalah kualitas pelayanan yaitu reliability, responsiveness, assurance, emphaty dan tangible. Pelayanan kualitas dapat dipandang dari penyedia layanan/jasa dan pengguna layanan itu sendiri. Namun dalam mengukur tingkat kepuasan pelanggan dalam pelayanan yang diberikan oleh PO Rosalia Indah, dibutuhkan penelitian lebih lanjut mengenai atributatribut yang dapat memberikan kepuasan dalam menggunakan jasa transportasi angkutan bus.

Kualitas pelayanan menjadi hal yang penting dalam memaksimalkan kepuasan pelanggan perusahaan. Pelayanan kualitas dapat dipandang dari penyedia layanan/jasa dan pengguna layanan itu sendiri. Namun dalam mengukur tingkat kepuasan pelanggan dalam pelayanan yang diberikan oleh PO Rosalia Indah, dibutuhkan penelitian lebih lanjut mengenai atributatribut yang dapat memberikan kepuasan dalam menggunakan jasa transportasi angkutan bus. Metode yang digunakan dalam penelitian ini adalah Importance Performance Competitor Analysis (IPCA) yang merupakan metode lanjutan dari IPA. IPCA mempertimbangkan keberadaan kompetitor dan menggunakan nilai performance difference dari perusahaan utama dan perusahaan pesaing dalam memberikan strategi berdasarkan pada kuadran yang diposisikan.

Tujuan penelitian ini adalah menganalisis atribut kualitas layanan PO Rosalia Indah terhadap pesaingnya yaitu PO Pahala Kencana, atribut kualitas layanan yang menjadi prioritas PO Rosalia Indah untuk menjadi strategi perusahaan agar mampu bersaing secara kompetitif, dan memberikan rekomendasi perbaikan terhadap atribut kualitas PO Rosalia Indah yang menjadi prioritas perbaikan perusahaan.

\section{Metode Penelitian}

Jumlah responden dalam penelitian ini adalah 223 orang dengan 117 pengguna Rosalia Indah dan 105 pengguna Pahala Kencana dan sesuai dengan ukuran minimal sampel berdasarkan tingkat kesalahan 10\% dan selang kepercayaan 95\%. Responden dipilih berdasarkan metode purposive sampling yaitu setiap responden yang dipilih memiliki kriteria tertentu yang berhak menjadi sampel atau mewakili populasi. Kriteria responden dalam penelitian ini adalah konsumen yang pernah merasakan layanan bus Rosalia Indah atau Pahala Kencana dengan jurusan Semarang-Jakarta dan kelas eksekutif. Responden pada penelitian ini tidak saling mempengaruhi sehingga responden Rosalia Indah berbeda dengan responden Pahala Kencana.

Berdasarkan metode IPCA, responden akan menilai tingkat kepentingan dan performansi dari setiap butir pernyataan yang diberikan dengan skala Likert 1-5 berdasarkan persepsi masing-masing responden yaitu $1=$ sangat tidak penting; $5=$ sangat penting untuk tingkat kepentingan dan $1=$ sangat tidak puas; $5=$ sangat puas untuk tingkat performansi. Terdapat tiga variabel yang dijadikan penelitian yaitu kendaraan, sopir dan kru dan manajemen. Masing-masing variabel kemudian dibagi kedalam beberapa butir pernyataan yang akan ditanyakan pada kuesioner yang berhubungan dengan perasaan penumpang selama menggunakan jasa dari 
kedua perusahaan otobus. Kuesioner akan dibagi kedalam dua bagian yaitu bagian pertama berisikan data demografi responden seperti nama, usia, jenis kelamin dan pekerjaan responden. Pada bagian kedua berisikan tingkat kepentingan dan tingkat performansi dari butir pernyataan yang diberikan oleh Rosalia Indah atau Pahala Kencana. Tingkat kepentingan digunakan untuk mengetahui seberapa penting butir pernyataan pada kuesioner yang diberikan terhadap kepuasan penumpang dan tingkat performansi digunakan untuk mengetahui kinerja sesungguhnya yang diberikan oleh perusahaan dan dirasakan oleh pelanggan ketika menikmati layanan jasa yang diberikan.

Hasil data yang didapatkan dari kuesioner kemudian dlakukan pengolahan data. Selain itu juga diberikan rekomendasi perbaikan layanan yang akan diberikan pada bagian ini berdasarkan tingkat perbaikan yang paling dibutuhkan oleh PO Rosalia Indah dari hasil penempatan atribut di kuadran. Penyusunan rekomendasi dalam penelitian ini menggunakan Nominal Group Technique (NGT). NGT digunakan sebagai metode dalam mencapai konsensus dalam suatu kelompok dengan cara mengumpulkan ide-ide dari setiap peserta, yang kemudian memberikan voting dan ranking terhadap ide-ide yang mereka pilih. NGT memiliki empat tahapan dalam pengambilan keputusan yaitu generating ideas, recording ideas, discussing ideas dan voting on ideas. Pada tahapan voting on ideas, peserta NGT akan memilih lima ide terbaik yang telah diusulkan untuk kemudian dilakukan ranking 1-5. Ranking dilakukan untuk menentukan prioritas dari kelima ide yang telah dipilih di mana nilai 1 untuk ide yang tidak penting dan 5 untuk ide yang penting.

Menurut Sample (1984), Nominal Group Techinique (NGT) adalah teknik brainstorming terstruktur yang digunakan untuk menghasilkan banyak ide yang berkaitan dengan masalah yang sedang dihadapi serta memastikan bahwa semua anggota memiliki partisipasi yang setara dalam mengembangkan ide-ide, kemudian memberikan voting dan ranking terhadap ide-ide yang mereka pilih. Teknik ini pada awalnya dikembangkan oleh Delbecq dan VandeVen yang sering digunakan untuk mengidentifikasi masalah dan menghasilkan solusi dari permasalahan tersebut. Keenam langkah dalam proses NGT yang diajukan oleh Jones pada tahun 2004 dalam Burrows, Findlay, Killen, Shaney, \& Hunter (2011) adalah peserta akan diminta untuk menuliskan ide (rekomendasi) tentang permasalahan yang dikemukakan. Lalu seluruh gagasan peserta dicatat. Selanjutnya diskusi kelompok tentang semua ide yang dihasilkan (untuk mengatur daftar dan menghapus duplikasi). Tahap berikutnya adalah pemungutan suara awal untuk memilih ide yang paling penting, kemudian diskusi kelompok tentang hasil pemungutan suara (termasuk penambahan dan penggabungan agar tidak terjadi tumpang tindih ide). Terakhir dilakukan pemungutan suara akhir menurut prioritas dari rekomendasi tersebut.

\section{Hasil Pengumpulan Data}

Berdasarkan data responden yang dikumpulkan maka didapat beberapa karakteristik responden yaitu jenis kelamin, pekerjaan dan umur. Berdasar Rosalia Indah dan Pahala Kencana, diketahui bahwa sebagian besar responden adalah laki-laki yaitu $77,7 \%$ untuk Rosalia Indah dan 69,5 \% untuk Pahala Kencana. Hal ini disebabkan masih adanya kesan kurang aman bagi wanita jika bepergian dengan menggunakan bus malam. Rata-rata umur responden Rosalia Indah adalah 20 tahun, sedangkan rata-rata umur responden perusahaan pesaing Pahala Kencana adalah 21 tahun. Penelitian ini dilakukan untuk mengukur pelayanan kualitas berdasarkan tiga dimensi dari Jomnonkwao dan Ratanavaraha (2016) yaitu dimensi 1: kendaraan (15 butir pernyataan), dimensi 2: sopir \& kru (8 butir pernyataan) dan dimensi 3 : manajemen (13 butir pernyataan). Untuk membandingkan perbedaan dalam menentukan strategi perusahaan maka langkah awal adalah dengan membuat matriks tradisional IPA.

Pada Tabel 1 merupakan rata-rata nilai untuk tingkat kepentingan dan performansi PO Rosalia Indah dan PO Pahala Kencana. Rata-rata nilai diperoleh dari jumlah seluruh penilaian skala Likert responden masing-masing karakteristik data dibagi dengan jumlah responden untuk masing-masing perusahaan otobus. Setelah dilakukan perhitungan rata-rata tiap karakteristik data maka dilakukan pemetaan dengan matriks tradisional IPA. Sumbu yang digunakan dalam matriks tradisional IPAadalah skala tengah $(2.5 ; 2.5)$ yang dibagi kedalam empat kuadran yaitu kuadran I keep up the good work, kuadran II possible overkill, kuadran III low priority dan kuadran IV concentrate here. Karakteristik data yang digunakan dalam membuat matriks tradisional IPA adalah nilai performansi dan kepentingan PO Rosalia Indah yang kemudian diposisikan kedalam kuadran tradisional IPA. Pada matriks tradisional IPA (Gambar 1) diketahui bahwa seluruh atribut masuk kedalam kuadran I yaitu keep up the good work.

\section{Hasil Pengolahan Data IPCA}

Matriks IPCA menggunakan Gap (kinerja dikurangi kepentingan PO Rosalia Indah) dan PD (kinerja PO Rosalia Indah dikurangi kinerja PO Pahala Kencana) yang dihitung untuk setiap butir pernyataan. Setiap butir pernyataan diposisikan pada matriks dengan nilai Gap sebagai sumbu y dan nilai PD sebagai sumbu $\mathrm{x}$. Matriks IPCA dilengkapi dengan dua garis dari titik 0 sumbu vertikal dan horizontal. Strategi perusahaan diperoleh untuk setiap butir pernyataan yang diposisikan pada analisis kuadran.

Tabel 2 merupakan hasil perhitungan nilai GAP dan PD yang akan digunakan dalam membuat matriks IPCA. Nilai negatif pada nilai GAP menunjukkan bahwa performansi yang diberikan oleh Rosalia Indah tidak dapat memenuhi harapan konsumen, sedangkan nilai negatif pada nilai PD menunjukkan bahwa performansi yang diberikan Rosalia Indah lebih rendah dibandingkan performansi yang diberikab oleh Pahala Kencana. Dari hasil pengolahan data diketahui terdapat 1 atribut untuk kuadran I solid competitive advantage, 12 atribut untuk kuadran II null advantage, 21 atribut untuk kuadran III urgent action dan 2 atribut untuk kuadran IV head-to-head competition. 
Tabel 1. Rata-Rata Butir Pernyataan

\begin{tabular}{|c|c|c|c|c|c|c|}
\hline Kode & Sumber & Butir Pernyataan & FB.P & CB.P & FB.I & CB.I \\
\hline K1 & \multirow{9}{*}{$\begin{array}{l}\text { Jomnonkwao } \\
\text { dan } \\
\text { Ratanavaraha } \\
\quad(2016)\end{array}$} & $\begin{array}{l}\text { Tidak ada suara mesin yang mengganggu dari } \\
\text { dalam bus }\end{array}$ & 4.00 & 4.05 & 4.45 & 4.36 \\
\hline $\mathrm{K} 2$ & & Kerapian dan Kebersihan didalam bus & 4.20 & 4.15 & 4.74 & 4.48 \\
\hline $\mathrm{K} 3$ & & $\begin{array}{l}\text { AC bekerja dengan baik (dingin, tidak bocor, } \\
\text { tidak bau) }\end{array}$ & 4.08 & 3.97 & 4.50 & 4.44 \\
\hline K4 & & $\begin{array}{l}\text { Jarak antar kursi dalam satu baris dapat } \\
\text { disesuaikan }\end{array}$ & 3.80 & 3.97 & 4.43 & 4.43 \\
\hline K5 & & $\begin{array}{l}\text { Terdapat fasilitas audio-video (TV, DVD Player, } \\
\text { MP3, Karaoke) di dalam bus }\end{array}$ & 3.84 & 3.77 & 3.68 & 3.54 \\
\hline K6 & & Sarana audio didalam bus bekerja baik & 3.88 & 3.97 & 3.83 & 3.70 \\
\hline K7 & & Penampilan fisik (body) bus dalam kondisi baik & 4.13 & 4.18 & 4.29 & 4.33 \\
\hline $\mathrm{K} 8$ & & Terdapat toilet yang bersih & 3.80 & 3.96 & 4.50 & 4.38 \\
\hline K9 & & $\begin{array}{l}\text { Terdapat peralatan keselamatan bus (alat } \\
\text { pemecah kaca, pintu darurat, alat pemadam api } \\
\text { ringan, fasilitas kesehatan) dengan instruksi. }\end{array}$ & 4.07 & 3.94 & 4.58 & 4.17 \\
\hline K10 & \multirow{3}{*}{$\begin{array}{l}\text { Jomnonkwao } \\
\text { dan } \\
\text { Ratanavaraha } \\
(2016)\end{array}$} & Terdapat gorden disetiap jendela bus & 4.14 & 4.26 & 4.21 & 4.14 \\
\hline $\mathrm{K} 11$ & & Nomor tempat duduk mudah dicari & 3.98 & 4.14 & 4.33 & 4.28 \\
\hline K12 & & $\begin{array}{l}\text { Penerangan atau Lampu dalam bus } \\
\text { bekerja dengan baik }\end{array}$ & 4.03 & 3.97 & 4.27 & 4.14 \\
\hline K13 & $\begin{array}{l}\text { Rachmawati, D., } \\
\text { Ristowati, T., } \\
\text { dan Khoeruddin, } \\
\text { M. (2013) }\end{array}$ & Terdapat fasilitas WIFI & 3.11 & 3.25 & 3.72 & 3.38 \\
\hline \multirow{2}{*}{$\begin{array}{l}\text { K14 } \\
\text { K15 }\end{array}$} & Sahara, A., & Fasilitas bagasi memadai & 4.11 & 3.99 & 4.26 & 4.17 \\
\hline & $\begin{array}{l}\text { Setyaningsih E., } \\
\text { Arifin, M. Z., \& } \\
\text { Kusumaningrum, } \\
\text { R. (2015) }\end{array}$ & Jendela dilapisi dengan kaca film & 3.91 & 4.01 & 3.86 & 3.93 \\
\hline SK1 & \multirow{12}{*}{$\begin{array}{l}\text { Jomnonkwao \& } \\
\text { Ratanavaraha } \\
\text { (2016) }\end{array}$} & Penampilan kru armada rapi dan bersih & 3.90 & 3.98 & 4.11 & 3.98 \\
\hline SK2 & & Kru armada memakai seragam perusahaan & 4.14 & 4.32 & 4.18 & 4.16 \\
\hline SK3 & & Kru membantu dengan ramah dan tanggap & 4.03 & 4.10 & 4.47 & 4.34 \\
\hline SK4 & & Kemampuan mengemudi sopir baik & 4.21 & 4.36 & 4.67 & 4.63 \\
\hline SK5 & & $\begin{array}{l}\text { Sopir bus mengemudi dengan aman (kecepatan } \\
\text { normal, mematuhi rambu lalu lintas) }\end{array}$ & 4.07 & 4.06 & 4.45 & 4.63 \\
\hline SK6 & & $\begin{array}{l}\text { Sopir dan Kru memiliki pengetahuan tentang } \\
\text { mesin jika terjadi kerusakan }\end{array}$ & 4.01 & 3.86 & 4.56 & 4.50 \\
\hline SK7 & & $\begin{array}{l}\text { Sopir bus memiliki pengetahuan tentang rute } \\
\text { perjalanan bus }\end{array}$ & 4.33 & 4.48 & 4.69 & 4.69 \\
\hline SK8 & & Sopir dan kru bekerja dengan on-time & 3.69 & 3.78 & 4.48 & 4.27 \\
\hline M1 & & $\begin{array}{l}\text { Terdapat layanan informasi (contact person) yang } \\
\text { mudah diakses. }\end{array}$ & 3.83 & 4.05 & 4.37 & 3.95 \\
\hline M2 & & Terdapat Global Positioning System (GPS) & 3.28 & 3.38 & 3.70 & 3.33 \\
\hline M3 & & Menyediakan 2 sopir untuk setiap bus & 4.11 & 4.17 & 4.44 & 4.22 \\
\hline M4 & & Penumpang menerima asuransi kecelakaan & 3.89 & 4.00 & 4.62 & 4.21 \\
\hline M5 & $\begin{array}{l}\text { Sahara, A., } \\
\text { Setyaningsih E., }\end{array}$ & $\begin{array}{l}\text { Fasilitas pengaduan bila ada keluhan pengguna } \\
\text { jasa }\end{array}$ & 3.74 & 3.79 & 4.42 & 4.02 \\
\hline M6 & Arifin, M. Z., \& & Jumlah penumpang sesuai kapasitas & 4.33 & 4.24 & 4.54 & 4.46 \\
\hline M7 & \multirow{2}{*}{$\begin{array}{l}\text { Kusumaningrum, } \\
\text { R. (2015) }\end{array}$} & Terdapat informasi kedatangan bus & 3.96 & 3.77 & 4.44 & 4.15 \\
\hline M8 & & Bus datang sesuai dengan jadwal keberangkatan & 3.44 & 3.67 & 4.45 & 4.32 \\
\hline M9 & $\begin{array}{l}\text { Rachmawati, D., } \\
\text { Ristowati, T., }\end{array}$ & $\begin{array}{l}\text { Penumpang diberi fasilitas tambahan (snack, air } \\
\text { minum, makan malam) }\end{array}$ & 3.82 & 3.96 & 4.29 & 4.27 \\
\hline M10 & dan Khoeruddin, & Terdapat informasi tentang fasilitas dalam bus & 3.48 & 3.57 & 3.99 & 3.89 \\
\hline M11 & M. (2013) & Adanya kemudahan dalam memesan tiket & 3.98 & 3.94 & 4.46 & 4.10 \\
\hline M12 & $\begin{array}{c}\text { Sahara, A., } \\
\text { Setyaningsih E., }\end{array}$ & Kemudahan akses menuju agen bus & 4.02 & 3.86 & 4.35 & 4.05 \\
\hline M13 & $\begin{array}{l}\text { Arifin, M. Z., \& } \\
\text { Kusumaningrum, } \\
\text { R. (2015) }\end{array}$ & $\begin{array}{l}\text { Kemudahan akses dari terminal/agen ke tujuan } \\
\text { utama }\end{array}$ & 4.01 & 3.88 & 4.36 & 4.11 \\
\hline
\end{tabular}


Keterangan:

FB.P = Focal Bus Performance

FB.I = Focal Bus Importance

CB.P $=$ Competitor Bus Performance

CB.I = Competitor Bus Importance

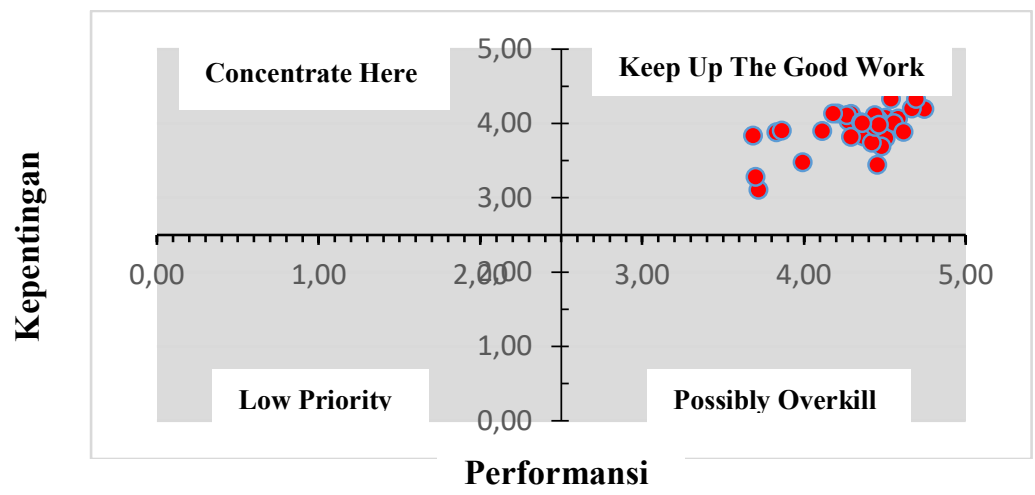

Gambar 1. Kuadran Matriks IPA

Tabel 2. Perbandingan Kuadran Matriks IPCA dan IPA

\begin{tabular}{|c|c|c|c|c|}
\hline Kode & GAP (FB.P - FB.I) & PD (FB.P - CB.P) & Kuadran IPCA & Kuadran IPA \\
\hline K1 & -0.45 & -0.05 & Urgent Action & Keep Up the Good Work \\
\hline $\mathbf{K} 2$ & -0.55 & 0.04 & Null Advantage & Keep Up the Good Work \\
\hline K3 & -0.43 & 0.11 & Null Advantage & Keep Up the Good Work \\
\hline K4 & -0.62 & -0.17 & Urgent Action & Keep Up the Good Work \\
\hline K5 & 0.15 & 0.07 & $\begin{array}{l}\text { Solid } \\
\text { Competitive } \\
\text { Advantage }\end{array}$ & Keep Up the Good Work \\
\hline K6 & 0.05 & -0.09 & $\begin{array}{l}\text { Head-to-head } \\
\text { Competition }\end{array}$ & Keep Up the Good Work \\
\hline $\mathbf{K} 7$ & -0.16 & -0.05 & Urgent Action & Keep Up the Good Work \\
\hline K8 & -0.70 & -0.16 & Urgent Action & Keep Up the Good Work \\
\hline K9 & -0.51 & 0.13 & Null Advantage & Keep Up the Good Work \\
\hline K10 & -0.07 & -0.12 & Urgent Action & Keep Up the Good Work \\
\hline K11 & -0.35 & -0.16 & Urgent Action & Keep Up the Good Work \\
\hline K12 & -0.24 & 0.06 & Null Advantage & Keep Up the Good Work \\
\hline K13 & -0.61 & -0.14 & Urgent Action & Keep Up the Good Work \\
\hline K14 & -0.15 & 0.12 & Null Advantage & Keep Up the Good Work \\
\hline K15 & 0.04 & -0.10 & $\begin{array}{l}\text { Head-to-head } \\
\text { Competition }\end{array}$ & Keep Up the Good Work \\
\hline SK1 & -0.21 & -0.08 & Urgent Action & Keep Up the Good Work \\
\hline SK2 & -0.04 & -0.19 & Urgent Action & Keep Up the Good Work \\
\hline SK3 & -0.44 & -0.07 & Urgent Action & Keep Up the Good Work \\
\hline SK4 & -0.46 & -0.16 & Urgent Action & Keep Up the Good Work \\
\hline SK5 & -0.38 & 0.01 & Null Advantage & Keep Up the Good Work \\
\hline SK6 & -0.55 & 0.15 & Null Advantage & Keep Up the Good Work \\
\hline SK7 & -0.36 & -0.14 & Urgent Action & Keep Up the Good Work \\
\hline SK8 & -0.79 & -0.09 & Urgent Action & Keep Up the Good Work \\
\hline M1 & -0.54 & -0.22 & Urgent Action & Keep Up the Good Work \\
\hline M2 & -0.42 & -0.10 & Urgent Action & Keep Up the Good Work \\
\hline M3 & -0.32 & -0.06 & Urgent Action & Keep Up the Good Work \\
\hline M4 & -0.73 & -0.11 & Urgent Action & Keep Up the Good Work \\
\hline M5 & -0.68 & -0.05 & Urgent Action & Keep Up the Good Work \\
\hline M6 & -0.21 & 0.10 & Null Advantage & Keep Up the Good Work \\
\hline M7 & -0.48 & 0.19 & Null Advantage & Keep Up the Good Work \\
\hline M8 & -1.01 & -0.22 & Urgent Action & Keep Up the Good Work \\
\hline M9 & -0.47 & -0.14 & Urgent Action & Keep Up the Good Work \\
\hline M10 & -0.51 & -0.09 & Urgent Action & Keep Up the Good Work \\
\hline M11 & -0.48 & 0.04 & Null Advantage & Keep Up the Good Work \\
\hline M12 & -0.33 & 0.16 & Null Advantage & Keep Up the Good Work \\
\hline M13 & -0.35 & 0.13 & Null Advantage & Keep Up the Good Work \\
\hline
\end{tabular}




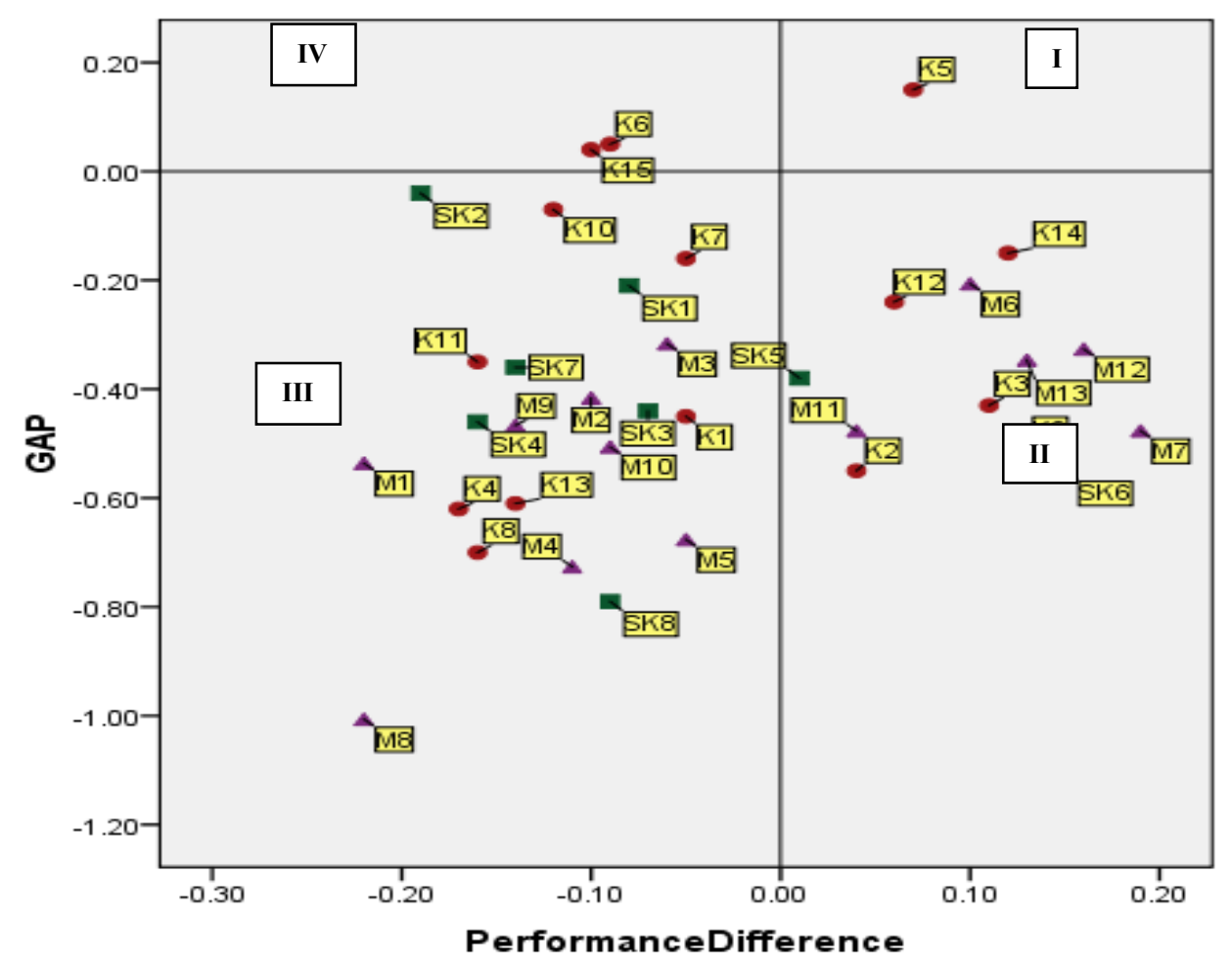

Gambar 2. Kuadran Matriks IPCA

\section{Rekomendasi Perbaikan}

Rekomendasi perbaikan dilakukan terhadap butir pernyataan yang masuk kedalam kuadran Urgent Action pada matriks IPCA. Rekomendasi ini dilakukan dengan menggunakan metode Numerical Group Technique (NGT). Rekomendasi perbaikan didapatkan dari Kepala Seksi Fasilitas dan Staff Divisi Angkutan Jalan Dinas Perhubungan, Komunikasi dan Informasi Provinsi Jawa Tengah, Koordinator Wilayah, Wakil Koordinator Wilayah dan Humas Bismania.com. Dari 21 usulan rekomendasi yang diberikan oleh seluruh peserta dipilh lima rekomendasi perbaikan yang terbaik untuk kemudian dilakukan ranking atau voting. Lima rekomendasi yang terbaik juga dipilih berdasarkan prioritas masalah yang dihasilkan oleh matriks IPCA seperti pada Tabel 4. Setelah memilih lima ide paling penting maka responden diminta untuk meranking lima ide tersebut dengan nilai 1 untuk ide yang paling tidak penting dan nilai 5 untuk ide yang paling penting. Setelah dilakukan ranking maka seluruh ide diberikan total nilai untuk mengetahui ide rekomendasi perbaikan yang menjadi prioritas dilakukan PO Rosalia Indah seperti pada Tabel 3.

Berdasarkan voting atau pemungutan suara (Tabel 4) yang dilakukan untuk menentukan ranking atau prioritas rekomendasi perbaikan, maka didapatkan urutan prioritas perbaikan pelayanan $\mathrm{PO}$ Rosalia Indah dengan melihat total nilai hasil dari voting para responden seperti berikut ini:

1. Komitmen sopir dan kru dalam mengikuti pelatihan/penyegaran minimal satu kali dalam setahun. Pelatihan yang dapat diikuti adalah pelatihan pengemudi, pelatihan tentang attitude dalam melayani penumpang selama perjalanan, pelatihan tentang pengetahuan mesin sebagai pertolongan pertama ketika bus mengalami kendala.

2. Memasang stiker tentang informasi layanan pengaduan yang dapat diakses oleh penumpang apabila terjadi keluhan seperti nomor telepon dan atau SMS pengaduan. Stiker dapat dipasang dibody bus dengan ukuran yang dapat terbaca dengan jelas oleh penumpang.

3. Kru bus harus rutin untuk mengecek kondisi toilet agar tetap nyaman digunakan oleh penumpang bus seperti menyiram dan membersihkan toilet secara berkala minimal satu jam sekali

4. Memberitahukan kepada penumpang mengenai adanya asuransi kecelakaan kepada penumpang apabila terjadi kecelakaan selama perjalanan yaitu asuransi jasa marga $1,5 \%$ harga tiket. Hal ini bisa dilakukan dengan penulisan adanya asuransi kecelakaan pada tiket yang dapat terlihat langsung oleh penumpang bus.

5. Karyawan di agen penjualan lebih komitmen dalam memberitahukan penumpang mengenai keterlambatan yang terjadi. Apabila keterlambatan sudah terprediksi sebelum waktu berkumpulnya penumpang, maka agen dapat memberitahukan via telepon ataupun pesan singkat. 
Tabel 3. Prioritas Rekomendasi Perbaikan

\begin{tabular}{|c|c|c|}
\hline Kode & Masalah & Rekomendasi Perbaikan \\
\hline A & $\begin{array}{l}\text { Bus tidak datang sesuai } \\
\text { dengan jadwal } \\
\text { keberangkatan }\end{array}$ & $\begin{array}{l}\text { Karyawan di agen penjualan lebih komitmen dalam memberitahukan } \\
\text { penumpang mengenai keterlambatan yang terjadi. Apabila } \\
\text { keterlambatan sudah terprediksi sebelum waktu berkumpulnya } \\
\text { penumpang, maka agen dapat memberitahukan via telepon ataupun } \\
\text { pesan singkat. }\end{array}$ \\
\hline B & $\begin{array}{l}\text { Sopir dan kru bekerja } \\
\text { dengan tidak ontime }\end{array}$ & $\begin{array}{l}\text { Komitmen sopir dan kru dalam mengikuti pelatihan/penyegaran } \\
\text { minimal } 1 \text { kali dalam setahun. Pelatihan yang dapat diikuti adalah } \\
\text { pelatihan pengemudi, pelatihan tentang attitude dalam melayani } \\
\text { penumpang selama perjalanan, pelatihan tentang pengetahuan mesin } \\
\text { sebagai pertolongan pertama ketika bus mengalami kendala. }\end{array}$ \\
\hline $\mathrm{C}$ & $\begin{array}{l}\text { Penumpang menerima } \\
\text { asuransi kecelakaan }\end{array}$ & $\begin{array}{l}\text { Memberitahukan kepada penumpang mengenai adanya asuransi } \\
\text { kecelakaan kepada penumpang apabila terjadi kecelakaan selama } \\
\text { perjalanan yaitu asuransi jasa marga } 1,5 \% \text { harga tiket. Hal ini bisa } \\
\text { dilakukan dengan penulisan adanya asuransi kecelakaan pada tiket } \\
\text { yang dapat terlihat langsung oleh penumpang bus. }\end{array}$ \\
\hline $\mathrm{D}$ & $\begin{array}{l}\text { Toilet dalam bus sering } \\
\text { tidak dalam keadaan } \\
\text { bersih }\end{array}$ & $\begin{array}{l}\text { Kru bus harus rutin untuk mengecek kondisi toilet agar tetap nyaman } \\
\text { digunakan oleh penumpang bus seperti menyiram dan membersihkan } \\
\text { toilet secara berkala minimal } 1 \text { jam sekali }\end{array}$ \\
\hline $\mathrm{E}$ & $\begin{array}{l}\text { Fasilitas pengaduan } \\
\text { apabila ada keluhan jasa } \\
\text { kurang tersedia }\end{array}$ & $\begin{array}{l}\text { Memasang stiker tentang informasi layanan pengaduan yang dapat } \\
\text { diakses oleh penumpang apabila terjadi keluhan seperti nomor telepon } \\
\text { dan atau SMS pengaduan. Stiker dapat dipasang dibody bus dengan } \\
\text { ukuran yang dapat terbaca dengan jelas oleh penumpang. }\end{array}$ \\
\hline
\end{tabular}

Tabel 4. Hasil Voting Rekomendasi Perbaikan

\begin{tabular}{cccccccc}
\hline Kode & Erry & Agus & Hakim & Wahyu & Adhit & Total Nilai & Prioritas \\
\hline A & 2 & 1 & 2 & 1 & 2 & 8 & V \\
B & 5 & 5 & 4 & 5 & 3 & 22 & I \\
C & 4 & 4 & 1 & 2 & 1 & 12 & IV \\
D & 2 & 2 & 3 & 3 & 4 & 14 & III \\
E & 3 & 3 & 5 & 4 & 5 & 20 & II \\
\hline
\end{tabular}

\section{Hasil dan Pembahasan}

Berdasarkan hasil pengolahan data serta pemetaan letak butir pernyataan dengan menggunakan IPA tradisional diketahui bahwa 36 butir pernyataan masuk kedalam kuadran Keep Up the Good Work (lihat Gambar 1). Kuadran ini memiliki butir pernyataan yang dianggap penting dalam menunjang kepuasan konsumen sehingga PO Rosalia Indah harus mempertahankan potensi kinerja tersebut. Salah satu butir pernyataan gap tertinggi adalah bus datang sesuai dengan jadwal keberangkatan. Hal ini sama dengan penelitian Sahara, A., Setyaningsih E., Arifin, M. Z., \& Kusumaningrum, R. (2015) di mana berdasarkan pengamatan yang dilakukan selama penelitian menunjukkan seringkali bus mengalami keterlambatan kedatangan dari 30 menit hingga 90 menit. Hal ini dapat disebabkan oleh bus merupakan moda transportasi yang tidak memiliki jalur transportasi sendiri sehingga rawan terjadi kemacetan dan mengakibatkan ikut terlambatnya keberangkatan penumpang dari agen bus. Namun hal tersebut bukanlah menjadi sesuatu yang jarang terjadi sehingga penumpang masih dapat memakluminya dan menjadi risiko menggunakan bus.

Hasil matriks PCA (lihat Gambar 2) menunjukkan 21 dari 36 butir pernyataan PO rosalia Indah diposisikan dalam kuadran Urgent Action. Hal ini menunjukkan butir pernyataan ini memiliki nilai Gap dan PD negatif yaitu PO Rosalia Indah tidak dapat mempertemukan keinginan atau harapan konsumen serta memiliki kinerja yang lebih rendah dari PO Pahala Kencana. Oleh karena banyaknya atribut yang masuk kedalam kuadran Urgent Action maka perusahaan harus membuat prioritas perbaikan dari seluruh butir pernyataan tersebut. Jarak dari titik 0 merupakan menjadi keputusan perusahaan dalam menentukan butir pernyataan yang menjadi prioritas untuk diperbaiki. Berdasarkan metode pengambilan prioritas maka Gambar 2 menunjukkan bahwa bus datang sesuai dengan jadwal keberangkatan menjadi prioritas pertama untuk segera diperbaiki yang kemudian disusul dengan sopir dan kru bekerja dengan ontime. Dari 21 butir pernyataan pada kuadran Urgent Action, diposisikan pada kuadran Keep Up the Good Work pada kuadran IPA tradisional. Perbedaan ini disebabkan oleh matriks IPA tradisional tidak mempertimbangkan keberadaan kompetitor.

Hanya satu butir pernyataan yang diposisikan kedalam kuadran Solid Competitive Advantage di mana nilai GAP dan PD nya positif. Butir pernyataan yang masuk dalam kuadran ini adalah terdapat fasilitas audiovideo (TV, DVD Player, MP3, Karaoke) didalam bus (K5). Butir pernyataan yang diposisikan dalam kuadran ini memberikan kekuatan dan keuntungan kompetitif bagi PO Rosalia Indah. Hal ini pun sama dengan hasil 
dari kuadran IPA yang memposisikan butir pernyataan ini pada Keep Up the Good Work.

Butir pernyataan yang diposisikan kedalam kuadran Head-to-head Competition adalah sarana audio didalam bus bekerja dengan baik (K6) dan jendela dilapisi dengan kaca film (K15). Butir pernyataan yang masuk kedalam kuadran ini telah memenuhi harapan pelanggan walaupun kinerja yang diberikan PO Rosalia Indah lebih rendah daripada pesaingnya yaitu PO Pahala Kencana. Hal ini menunjukkan bahwa kekuatan PO Rosalia Indah sudah baik namun perlu peningkatan sehingga dapat memiliki performansi lebih baik dibandingkan pesaingnya.

Butir pernyataan yang diposisikan kedalam kuadran Null Advantage adalah sebanyak 12 butir pernyataan yaitu adanya kemudahan dalam memesan tiket, fasilitas bagasi memadai, jumlah penumpang sesuai kapasitas. Kuadran ini memiliki kerja PO Rosalia Indah lebih tinggi dibandingkan dengan PO Pahala Kencana namun harapan atau keinginan konsumen tidak dapat dipenuhi atau melebihi harapan. Dengan menggunakan IPA, perusahaan Rosalia Indah bisa saja melakukan ketidak akuratan dalam mengambil keputusan terhadap fasilitas pelayanan yang dimilikinya. Oleh karena itu IPCA memberikan strategi berbeda dalam menentukan prioritas perbaikan yang dapat dilakukan perusahaan terhadap fasilitas-fasilitas yang dimilikinya.

\section{Kesimpulan}

Kesimpulan dari penelitian ini adalah berdasarkan pengolahan data dengan mencari nilai Performance Difference menggunakan matriks IPCA diketahui 13 butir pernyataan atau pelayanan fasilitas PO Rosalia Indah lebih unggul dibandingkan dengan Pahala Kencana seperti kerapian dan kebersihan dalam bus baik, fasilitas bagasi memadai, sopir bus mengemudi dengan aman seperti kecepatan normal dan patuh rambu lalu lintas. Salah satu pelayanan PO Rosalia Indah yang memiliki gap positif tertinggi adalah terdapat informasi kedatangan bus lebih baik dibandingkan PO Pahala Kencana. Penentuan prioritas perbaikan dilakukan terhadap butir pernyataan yang masuk kedalam kuadran Urgent Action dan memiliki titik terjauh dari null point (titik 0). Butir pernyataan yang memiliki prioritas tertinggi adalah bus datang sesuai dengan jadwal keberangkatan, sopir dan kru bekerja dengan on-time, penumpang menerima asuransi kecelakaan, terdapat toilet yang bersih, fasilitas pengaduan bila ada keluhan pengguna jasa

Penentuan rekomendasi perbaikan dilakukan dengan menggunakan metode Numerical Group Technique yaitu teknik brainstorming yang terstruktur yang melibatkan peserta yang paham dengan permasalahan untuk mendapatkan prioritas usulan rekomendasi berdasarkan voting atau ranking lima ide terbaik.Rekomendasi perbaikan yang dapat dilakukan PO Rosalia Indah adalah meningkatkan pelayanan kinerjanya adalah sopir dan kru mengikuti pelatihan/penyegaran minimal satu tahun sekali, memasang stiker informasi kontak layanan pengaduan pada body dan kaca bus, pengecekan kebersihan toilet minimal satu jam sekali, menginformasikan adanya asuransi kecelakaan dengan ukuran tulisan yang jelas pada tiket, dan pemberitahuan keterlambatan keberangkatan via pesan singkat atau telepon. Hal ini pun sama seperti penelitian Rachmawati, D., Ristowati, T., dan Khoeruddin, M. (2013) yang memberikan rekomendasi mengenai fasilitas toilet dan adanya fasilitas pengaduan keluhan.

Saran untuk penelitian selanjutnya dapat mempertimbangkan perusahaan otobus lainnya sehingga dapat mengetahui konsistensi kinerja PO Rosalia Indah apabila mempertimbangkan perusahaan otobus lainnya. Penelitian selanjutnya juga dapat dilakukan dengan objek penelitian yang lebih spesifik yaitu dengan menggunakan satu trayek atau tujuan utama penumpang bus.

\section{Daftar Pustaka}

Burrows, T., Findlay, N., Killen, C., Shaney, E.D., \& Hunter, S. (2011). Using Nominal Group Technique to Develop a Consensus Derived Model for Peer Review of Teaching Across a Multi-School Faculty, Journal of University Teaching \& Learning Practice, Vo. 8, Issue 2, 2011.

Cahyaningrum, S. Y. \& Werdiono, D. (2015, July 15). Minat Pemudik Gunakan Bus Umum Makin Turun. Kompas, p.1. Retrieved from http://print.kompas.com/baca/2015/07/01/MinatPemudik-Gunakan-Bus-Umum-Makin-Turun.

Jomnonkwao, S., \& Ratanavaraha, V. (2016). Measurement modelling of the perceived service quality of a sightseeing bus service: An application of hierarchical confirmatory faktor analysis. Transport Policy, 45, 240-252.

Putri, Kadek Indri Novita Sari dan I Nyoman Nurcaya. (2013). Pengaruh Dimensi Kualitas Pelayanan Jasa Terhadap Kepuasan Pelanggan D \& I Skin Centre Denpasar. E-Jurnal Manajemen Universitas Udayana. 2, 918-936.

Rachmawati, D., Ristowati, T., dan Khoeruddin, M. (2013). Analysis Service of Satisfacrion of Intercity bus with IPA and CSI Method. In R. Maulidya \& E. Wahyono (Ed.) The $6^{\text {th }}$ International Seminar on Industrial Engineering and Management ( $6^{\text {th }}$ ISIEM) (6-10). Batam.

Sahara, A., Setyaningsih E., Arifin, M. Z., \& Kusumaningrum, R. (2015). Kajian Kinerja Operasional Bus Antar Kota Antar Provinsi (AKAP) Kelas Eksekutif Trayek Malang-Jakarta. Jurnal Mahasiswa Jurusan Teknik Sipil, 1, 1-12.

Sample, J. (1984) Nominal Group Technique: An Alternative to Brainstorming. Journal of Extension, 22 (2).

Tjiptono, Fandy. (2008). Strategi Pemasaran. Yogyakarta : Andi. 